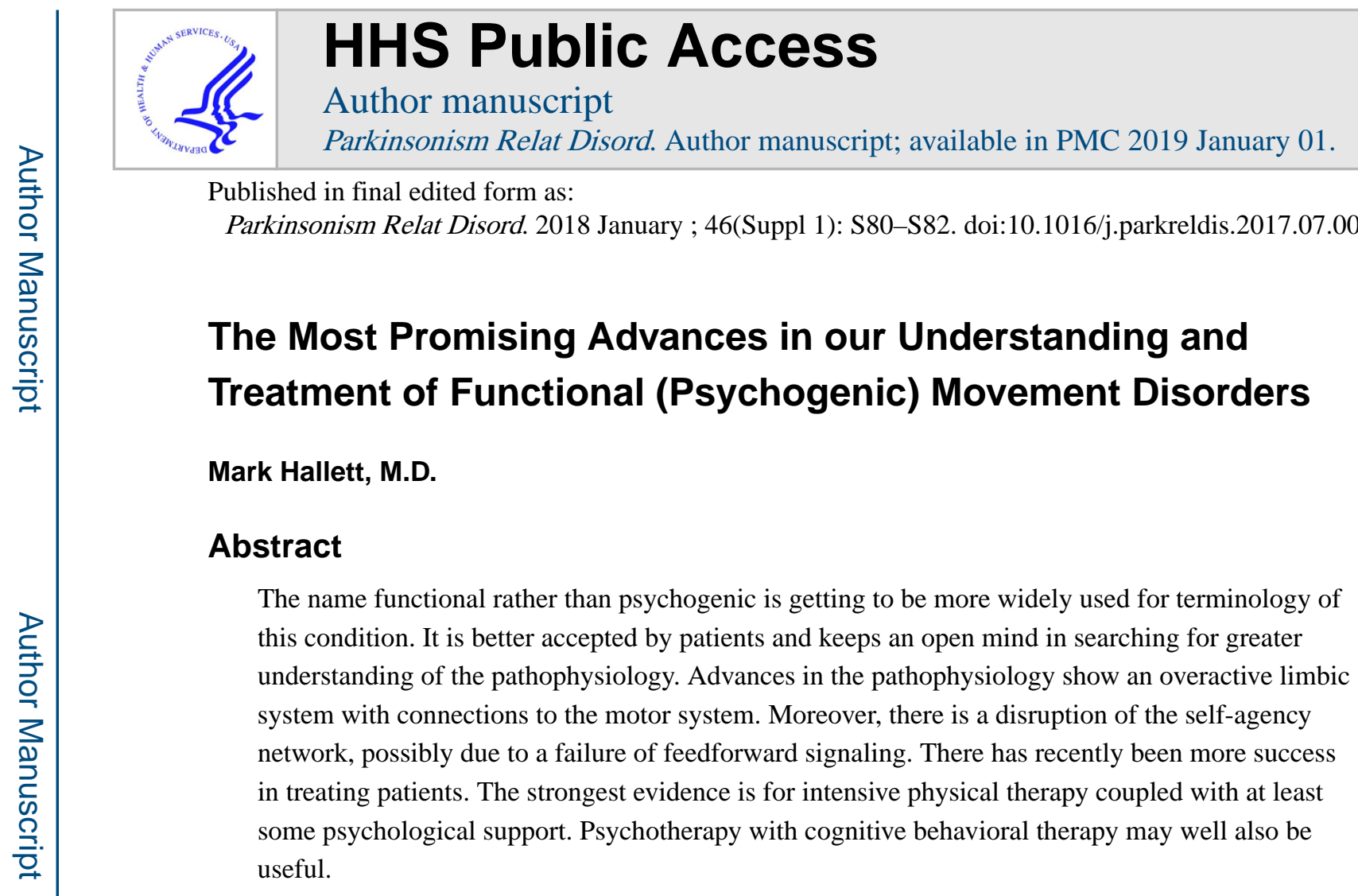

\title{
Keywords
}

Functional movement disorder; psychogenic movement disorder; limbic system; neuroimaging; pathophysiology; treatment; physical therapy; agency

The understanding and treatment of functional movement disorders is making rapid progress. After a long period of neglect, neurologists and psychiatrists are again directing their attention to this common disorder. Indeed, there is more interest in functional neurologic disorders in general, and recently a volume of the Handbook of Clinical Neurology has been devoted entirely to these disorders [1]. In addition to this book, I have recently reviewed the general nature of these disorders and the best way to make the clinical diagnosis for this journal [2], and only selected topics will be considered here.

There has been a shift in the name of the disorder [3]. In recent years, the term psychogenic movement disorder had been most common, but now functional movement disorder is more often used. This remains controversial, but the term functional has been adopted by the DSM-5 which includes Conversion Disorder, or Functional Neurological Symptom Disorder, under the general category of Somatic Symptom and Related Disorders.

Correspondence with: Mark Hallett, M.D., Dr.Med.h.c., Chief, Human Motor Control Section, NINDS, NIH, Building 10, Room 7D37, 10 Center Drive, Bethesda, MD 20892-1428, Tel: 301-496-9526, FAX: 301-480-2286, hallettm@ ninds.nih.gov. There is no relevant conflict of interest.

Full conflict of Interest: Dr. Hallett serves as Chair of the Medical Advisory Board for and receives honoraria and funding for travel from the Neurotoxin Institute. He may accrue revenue on US Patent: Immunotoxin (MAB-Ricin) for the treatment of focal movement disorders, and US Patent: Coil for Magnetic Stimulation and methods for using the same (H-coil); in relation to the latter, he has received license fee payments from the NIH (from Brainsway) for licensing of this patent. Dr. Hallett's research at the NIH is largely supported by the NIH Intramural Program. Supplemental research funds have been granted by Medtronics, Inc., for studies of deep brain stimulation, UniQure for a clinical trial of AAV2-GDNF for Parkinson Disease, Merz for treatment studies of focal hand dystonia, and Allergan for studies of methods to inject botulinum toxins. 
Arguments for maintaining the term psychogenic include that, since the disorder has a psychological cause, we should call a spade a spade, and that the term functional is ambiguous with several meanings in different contexts. Arguments for change are that we really do not know the cause and that specifying that there must be a psychological cause may irritate the patient (who might not be ready to hear this etiology) and ultimately might confuse current research into the nature of the disorder. A functional disorder can be described to the patient as a malfunction of an undamaged brain, giving some hope that the problem might be corrected more easily than if the brain was, for example, undergoing a degenerative process. Indeed, the term functional is a more acceptable term for patients than psychogenic [3].

\section{Biopsychosocial Model}

Functional movement disorders generally appear to have a multifactorial etiology, including some or all of three main etiologies: biological factors, psychological issues, and social situation. These factors can interact with each other. For example, persons with different underlying biology from genetic differences may react to social situation differently and perhaps lead to a psychiatric disorder. Different persons will develop different amounts of stress and anxiety in the same situation.

Early life stress, even stress of the mother when the child is in utero, can lead to problematic changes. Increased cortisol levels can lead to shrinkage of the hippocampus and epigenetic changes of specific genes that then predispose to psychiatric abnormalities. The first question is whether there is evidence for early life stress in patients with functional movement disorders. In our own study of 64 patients compared with healthy volunteers and patients with focal hand dystonia, the functional movement disorder patients had higher rates of total childhood trauma, greater fear associated with traumatic events and a greater number of traumatic episodes [4]. Emotional abuse, physical neglect, fear with traumatic events and the number of traumas were significant also after covarying for depression.

Current stress is often thought to be a factor in the precipitation and maintenance of a functional movement disorder. While patients often deny it, stress is often evident [5], although it must be noted that stress is common in today's world. An objective measure of current stress is the 24 hour cortisol levels. We studied 33 patients and matched controls with salivary cortisol levels at five times during the diurnal cycle [6]. There was no difference between groups. Thus, we could not identify objective evidence of higher amounts of stress in the patients. Stress may well play a role in some patients, but it might be the reaction to the stress rather than the "objective" amount of stress. This result also raises caution for the attending neurologists to not insist that stress is a problem for the patient (particularly if the patient does not agree).

There is indeed some evidence for a difficulty in dealing with stress. Heart rate monitoring for 14 to 24 hours revealed decreased root mean square of successive differences between adjacent NN intervals [7]. This is indicative of deficient vagal tone which correlates with impaired ability of the individual to adapt appropriately to environmental demands. 
Another social factor is secondary gain, and this is often noted in the patients' situations [5]. Sometimes it certainly seems that getting better from the disorder will put the person into a worse social situation, and this would reduce the motivation for getting well.

All studies agree that there is a high co-morbidity with anxiety and depression in these patients [4, 5], but there has been less clarity on personality features. Classically, there was said to be a "la belle indifference" to the disability, but this has not been a prominent feature in large series. In our study of personality traits in 59 patients [8], the only difference to healthy volunteers was the depression facet of the neuroticism scale (NEO-PI-R personality inventory), which indicates a greater "tendency to experience feelings of guilt, sadness, despondency and loneliness." (This study also compared the functional movement disorder patients to patients with psychogenic nonepileptic seizures and found that the seizure patients had more depression, anxiety, personality disturbance and more childhood stress.)

Neuroimaging studies are showing significant abnormalities of brain function in these patients. An early observation was a study of brain activation in patients with functional tremor, comparing their involuntary tremor with a voluntary mimicking of the tremor. The most prominent abnormality was a decreased of activation of the temporo-parietal junction (TPJ) during the involuntary tremor [9]. This observation seemed to explain the sense of involuntariness, since the TPJ is a relevant region generating the sense of self-agency for movement [10]. This finding has been supported by other studies. A resting state fMRI study of 35 patients compared with healthy volunteers showed decreased functional connectivity between the right TPJ and the right sensorimotor cortex, cerebellar vermis, bilateral supplementary motor area, and right insula [11]. Abnormal functioning of the TPJ and its related network was also shown with voluntary movements with experimenter externally varying the amount of agency [12]. Other evidence for a decrease in agency even with voluntary movements is that patients have decreased action-effect binding [13]. Specifically, the subjective times of button press and resultant tone did not move as much closer together for patients as it did for healthy volunteers.

There is also evidence for overactivity of the limbic system in these patients with increased connection to the motor system. Two studies have shown increased amygdala response to emotional faces with increased activity or connection to the supplementary motor area (SMA) $[14,15]$. With motor preparation, there was greater activity in the amygdala in patients than matched controls [16]. Another study of 10 patients with matched controls looked at the ability to maintain a constant grip force while viewing emotional images [17]. Normal subjects reduced force with unpleasant images, but patients preserved the force, perhaps indicating an effect of negative affect on movement. During this task, patients had greater activity in a cerebellar-limbic network than controls. The startle response was studied in 17 patients and 15 matched controls [18]. The startle response was similar in form but had increased amplitude in patients. The startle response is under control of the amygdala and, therefore, the result is compatible with increased limbic activity.

The picture is far from complete, but the evidence is accumulating for aberrant movement generation from an overactive limbic system and a failure of the network for self-agency. Since there is not much evidence for any abnormality of feedback (sensory processing) in 
the patients, a failure of self-agency would likely derive from an abnormal feedforward signal. If the limbic system is indeed triggering movement in an abnormal fashion, there might not be a proper feedforward signal.

\section{Treatment}

Treatment of these patients is often difficult, and prognosis generally has not been good. First, they might not accept the diagnosis and seek another opinion, presumably hoping to find an organic brain disease. Second, even when they accept the diagnosis, treatments are not well established and it is often difficult to find a psychiatrist knowledgeable and willing to help. However, there is progress [19].

The first step after making the diagnosis is telling the patient [20]. Each patient must be approached individually. The terminology may be important and the use of the term "functional," as noted earlier, is an advance. Explaining how the diagnosis was made including showing the patients the physical signs used to make the diagnosis can be helpful. Patients may not have heard about the diagnosis or do not know how common it is. Referring them to the website "www.neurosymptoms.org" can be helpful for their further education. Optimal treatment requires a multidisciplinary team including the neurologist, a psychiatrist, and possibly a physiatrist or physical therapist and social worker.

If a patient has significant co-morbid anxiety or depression, then pharmacotherapy might well be appropriate, and it has been demonstrated to be of value [21].

Psychotherapy of some sort seems necessary for most patients, and cognitive behavioral therapy (CBT) is currently popular although there is not good evidence for it in functional movement disorders. There is evidence for somatoform disorders in general, and for functional seizures specifically [22, 23]. A study of 29 patients, all of whom received CBT, showed motor improvement as well as benefits for anxiety and depression [24].

Physiotherapy has been studied in several trials, some of them large. A consensus recommendation for physiotherapy has been published by a UK group [25]. They suggest a comprehensive program of education and self-management in addition to movement retraining. In a study, employing this strategy, of 57 patients divided into physiotherapy for 5 days and treatment as usual, the physiotherapy group had $72 \%$ rating that they had improved versus $18 \%$ of the controls at 6 months [26]. An earlier large study of 60 patients just had intensive physical therapy for one week (compared with another 60 patients with treatment as usual), but prefaced the training with optimism that the therapy could fix a "disconnect" between a normal brain and normal muscles [27]. There was good improvement with $60.4 \%$ improved at a mean of 25 months compared with $21.9 \%$ in the control group. Not all studies are positive; for example, one study found that physical therapy did not provide added benefit to CBT [24].

In small studies of psychodynamic psychotherapy, one uncontrolled study showed benefit [28], while another in a randomized control trial did not [29]. There has been some anecdotal evidence for therapeutic sedation and one open trial of 11 patients using propofol in a standardized technique [30]. Five improved and maintained benefit at follow up at a 
mean of 30 months. This deserves more attention. There have been a few small studies of transcranial magnetic stimulation of the motor cortex or premotor cortex without encouraging results [19]. While patients can be highly suggestible and show short term placebo responses, use of placebo over long periods has some ethical concerns, and while there are no good long term studies, anecdotal evidence is that in most cases any effect is lost over a relatively short period.

\section{Conclusion}

There has been substantial progress in this area. Our increased understanding of the pathophysiology can be seen to be consistent with the "classical view" that the disorder arises due to emotional problems. An overactivity of the limbic system is consistent with emotional problems, but might arise from other etiologies such as a difference in brain development. Approaching treatment with psychotherapy can be valuable, and this makes sense, but there might well be other avenues directly focused on the biology - not forgetting to also deal with the psychosocial aspects of the patient. In medical school, doctors are taught to treat the whole patient, and this is a situation where that lesson is certainly necessary.

\section{Acknowledgments}

Supported by the NINDS Intramural Program.

\section{References}

1. Hallett, M., Stone, J., Carson, A. Functional Neurologic Disorders. Elsevier; Amsterdam: 2016.

2. Hallett M. Functional (psychogenic) movement disorders - Clinical presentations. Parkinsonism Relat Disord. 2016; 22(Suppl 1):S149-52. [PubMed: 26365778]

3. Edwards MJ, Stone J, Lang AE. From psychogenic movement disorder to functional movement disorder: It's time to change the name. Mov Disord. 2014; 29(7):849-52. [PubMed: 23843209]

4. Kranick S, Ekanayake V, Martinez V, Ameli R, Hallett M, Voon V. Psychopathology and psychogenic movement disorders. Mov Disord. 2011; 26(10):1844-50. [PubMed: 21714007]

5. Epstein SA, Maurer CW, LaFaver K, Ameli R, Sinclair S, Hallett M. Insights into Chronic Functional Movement Disorders: The Value of Qualitative Psychiatric Interviews. Psychosomatics. 2016; 57(6):566-575. [PubMed: 27377316]

6. Maurer CW, LaFaver K, Ameli R, Toledo R, Hallett M. A biological measure of stress levels in patients with functional movement disorders. Parkinsonism Relat Disord. 2015; 21(9):1072-5. [PubMed: 26117436]

7. Maurer CW, Liu VD, LaFaver K, Ameli R, Wu T, Toledo R, Epstein SA, Hallett M. Impaired resting vagal tone in patients with functional movement disorders. Parkinsonism Relat Disord. 2016; 30:18-22. [PubMed: 27334304]

8. Ekanayake V, Kranick S, LaFaver K, Naz A, Frank Webb A, LaFrance WC Jr, Hallett M, Voon V. Personality traits in psychogenic nonepileptic seizures (PNES) and psychogenic movement disorder (PMD): Neuroticism and perfectionism. J Psychosom Res. 2017; 97:23-29. [PubMed: 28606495]

9. Voon V, Gallea C, Hattori N, Bruno M, Ekanayake V, Hallett M. The involuntary nature of conversion disorder. Neurology. 2010; 74:223-228. [PubMed: 20083798]

10. Nahab FB, Kundu P, Gallea C, Kakareka J, Pursley R, Pohida T, Miletta N, Friedman J, Hallett M. The neural processes underlying self-agency. Cereb Cortex. 2011; 21(1):48-55. [PubMed: 20378581] 
11. Maurer CW, LaFaver K, Ameli R, Epstein SA, Hallett M, Horovitz SG. Impaired self-agency in functional movement disorders: A resting-state fMRI study. Neurology. 2016; 87(6):564-70. [PubMed: 27385746]

12. Nahab FB, Kundu P, Maurer C, Shen Q, Hallett M. Impaired sense of agency in functional movement disorders: An fMRI study. PLoS One. 2017; 12(4):e0172502. [PubMed: 28448504]

13. Kranick SM, Moore JW, Yusuf N, Martinez VT, LaFaver K, Edwards MJ, Mehta AR, Collins P, Harrison NA, Haggard P, Hallett M, Voon V. Action-effect binding is decreased in motor conversion disorder: implications for sense of agency. Mov Disord. 2013; 28(8):1110-6. [PubMed: 23494975]

14. Voon V, Brezing C, Gallea C, Ameli R, Roelofs K, LaFrance WC Jr, Hallett M. Emotional stimuli and motor conversion disorder. Brain. 2010; 133(Pt 5):1526-36. [PubMed: 20371508]

15. Aybek S, Nicholson TR, O’Daly O, Zelaya F, Kanaan RA, David AS. Emotion-motion interactions in conversion disorder: an FMRI study. PLoS One. 2015; 10(4):e0123273. [PubMed: 25859660]

16. Voon V, Brezing C, Gallea C, Hallett M. Aberrant supplementary motor complex and limbic activity during motor preparation in motor conversion disorder. Mov Disord. 2011; 26(13):2396403. [PubMed: 21935985]

17. Blakemore RL, Sinanaj I, Galli S, Aybek S, Vuilleumier P. Aversive stimuli exacerbate defensive motor behaviour in motor conversion disorder. Neuropsychologia. 2016; 93(Pt A):229-241. [PubMed: 27842291]

18. Dreissen YEM, Boeree T, Koelman J, Tijssen MAJ. Startle responses in functional jerky movement disorders are increased but have a normal pattern. Parkinsonism Relat Disord. 2017; 40:27-32. [PubMed: 28410805]

19. Ricciardi L, Edwards MJ. Treatment of functional (psychogenic) movement disorders. Neurotherapeutics. 2014; 11(1):201-7. [PubMed: 24356785]

20. Stone J, Carson A, Hallett M. Explanation as treatment for functional neurologic disorders. Handbook of Clinical Neurology. 2016; 139:543-553. [PubMed: 27719870]

21. Voon V, Lang AE. Antidepressant Treatment Outcomes of Psychogenic Movement Disorder. J Clin Psychiatry. 2005; 66(12):1529-1534. [PubMed: 16401153]

22. LaFrance WC Jr, Baird GL, Barry JJ, Blum AS, Frank Webb A, Keitner GI, Machan JT, Miller I, Szaflarski JP. N.E.S.T.T. Consortium. Multicenter pilot treatment trial for psychogenic nonepileptic seizures: a randomized clinical trial. JAMA Psychiatry. 2014; 71(9):997-1005. [PubMed: 24989152]

23. Cope SR, Smith JG, King T, Agrawal N. Evaluation of a pilot innovative cognitive-behavioral therapy-based psychoeducation group treatment for functional non-epileptic attacks. Epilepsy Behav. 2017; 70(Pt A):238-244. [PubMed: 28454061]

24. Dallocchio C, Tinazzi M, Bombieri F, Arno N, Erro R. Cognitive Behavioural Therapy and Adjunctive Physical Activity for Functional Movement Disorders (Conversion Disorder): A Pilot, Single-Blinded, Randomized Study. Psychother Psychosom. 2016; 85(6):381-383. [PubMed: 27744440]

25. Nielsen G, Stone J, Matthews A, Brown M, Sparkes C, Farmer R, Masterton L, Duncan L, Winters A, Daniell L, Lumsden C, Carson A, David AS, Edwards M. Physiotherapy for functional motor disorders: a consensus recommendation. J Neurol Neurosurg Psychiatry. 2015; 86(10):1113-9. [PubMed: 25433033]

26. Nielsen G, Buszewicz M, Stevenson F, Hunter R, Holt K, Dudziec M, Ricciardi L, Marsden J, Joyce E, Edwards MJ. Randomised feasibility study of physiotherapy for patients with functional motor symptoms. J Neurol Neurosurg Psychiatry. 2017; 88(6):484-490. [PubMed: 27694498]

27. Czarnecki K, Thompson JM, Seime R, Geda YE, Duffy JR, Ahlskog JE. Functional movement disorders: Successful treatment with a physical therapy rehabilitation protocol. Parkinsonism Relat Disord. 2012; 18(3):247-51. [PubMed: 22113131]

28. Hinson VK, Weinstein S, Bernard B, Leurgans SE, Goetz CG. Single-blind clinical trial of psychotherapy for treatment of psychogenic movement disorders. Parkinsonism Relat Disord. 2006; 12(3):177-80. [PubMed: 16364676] 
29. Kompoliti K, Wilson B, Stebbins G, Bernard B, Hinson V. Immediate vs. delayed treatment of psychogenic movement disorders with short term psychodynamic psychotherapy: randomized clinical trial. Parkinsonism Relat Disord. 2014; 20(1):60-3. [PubMed: 24120952]

30. Stone J, Hoeritzauer I, Brown K, Carson A. Therapeutic sedation for functional (psychogenic) neurological symptoms. J Psychosom Res. 2014; 76(2):165-8. [PubMed: 24439694] 


\section{Highlights}

Functional movement disorder is preferred rather than psychogenic movement disorder.

Understanding of the pathophysiology requires a biopsychosocial model.

There is evidence for an overactive limbic system and failure of self-agency.

There are advances in the treatments for these patients. 